(C) 2020, The Authors. Published by Elsevier Inc. and Fass Inc. on behalf of the American Dairy Science Association ${ }^{\circledR}$. This is an open access article under the CC BY-NC-ND license (http://creativecommons.org/licenses/by-nc-nd/4.0/).

\title{
Microbiota of bovine milk, teat skin, and teat canal: Similarity and variation due to sampling technique and milk fraction
}

\author{
J. Dahlberg, ${ }^{1 *}$ J. E. Williams, ${ }^{2}$ M. A. McGuire, ${ }^{2}$ H. K. Peterson, ${ }^{2}$ K. Östensson, ${ }^{3}$ S. Agenäs, ${ }^{1}$ J. Dicksved, ${ }^{1}$ \\ and K. Persson Waller ${ }^{3,4}$ \\ ${ }^{1}$ Department of Animal Nutrition and Management, Swedish University of Agricultural Sciences, 75007 Uppsala, Sweden \\ ${ }^{2}$ Department of Animal and Veterinary Science, University of Idaho, Moscow 83844 \\ ${ }^{3}$ Department of Clinical Sciences, Swedish University of Agricultural Sciences, 75007 Uppsala, Sweden \\ ${ }^{4}$ Department of Animal Health and Antimicrobial Strategies, National Veterinary Institute, 75189 Uppsala, Sweden
}

\section{ABSTRACT}

The aim of this study was to evaluate the effect of sampling technique and milk fraction on bovine milk microbiota data and to compare the microbiota in milk to microbiota on the teat end and in the teat canal. Representative milk samples are highly important for assessment of bacteriological findings and microbiota in milk. Samples were obtained from 5 healthy lactating dairy cows at udder quarter level during 1 milking. Swab samples from the teat end and teat canal, and milk samples collected using different techniques and in different milk fractions were included. Milk was collected by hand stripping and through a teat canal cannula before and after machine milking, through a trans-teat wall needle aspirate after milking, and from udder quarter composite milk. The microbiota of the samples was analyzed with sequencing of the V1-V3 region of the $16 \mathrm{~S}$ rRNA gene. In addition, somatic cell counts and bacterial cultivability were analyzed in the milk samples. Microbiota data were analyzed using multivariate methods, and differences between samples were tested using analysis of similarity (ANOSIM). Differences between samples were further explored via individual studies of the 10 most abundant genera. The microbiota on the teat end, in the teat canal, and in udder quarter composite milk, collected using a milking machine, differed in composition from the microbiota in milk collected directly from the udder quarter. No differences in milk microbiota composition were detected between hand-stripped milk samples, milk samples taken through a teat canal cannula, or milk samples taken as a trans-teat wall needle aspirate before or after milking. We conclude that for aseptic milk samples collected directly from the lactating udder quarter,

Received October 23, 2019.

Accepted April 7, 2020.

*Corresponding author: Josef.Dahlberg@slu.se sampling technique or milk fraction has minor effect on the microbiota composition.

Key words: milk microbiota, milk sampling technique, cannula, 16S rRNA

\section{INTRODUCTION}

Representative milk samples are highly important for assessment of bacteriological findings in bovine milk. Sampling technique has been shown to have an effect on microorganisms found through culturing and $\mathrm{qPCR}$ in bovine milk. Several studies have compared the bacteriological findings in conventionally taken hand-stripped milk samples to findings in milk collected without passing through the teat canal. Bexiga et al. (2011) found less growth of Corynebacterium spp. in milk samples taken via a cannula inserted in the teat canal compared with conventional hand-stripped milk samples. Friman et al. (2017) found fewer bacterial species, fewer Staphylococcus spp., less Trueperella pyogenes, and less yeast in milk samples taken with a cannula compared with conventional hand-stripped milk samples in a qPCR-based study. Hiitiö et al. (2016) bypassed the teat canal by taking milk samples directly from the quarter gland cistern using a needle fitted to a vacuum tube and compared the bacteriological findings against conventional hand-stripped milk samples using qPCR. They found more bacterial species per sample and more Staphylococcus spp. in samples collected by handstripping. However, the number of studies investigating the effect of sampling technique on the microbiota of bovine milk as analyzed by $16 \mathrm{~S}$ rRNA gene sequencing, which, in theory, should return all bacterial taxa present in a sample, is limited. Metzger et al. (2018a), using the same sampling techniques as Hiitiö et al. (2016) and analyzing the bacterial composition by sequencing of the 16S rRNA gene, observed an increased Chao bacterial richness in composite milk samples compared with conventional hand-stripped or needle aspirates but no difference in $\beta$-diversity. The microbiota of the 
teat end and the teat canal has been investigated with culture-dependent and culture-independent techniques (Gill et al., 2006; Braem et al., 2012; Verdier-Metz et al., 2012; Falentin et al., 2016; Doyle et al., 2017; Derakhshani et al., 2018). These studies have rarely included comparisons of the microbiota of the teat end or the teat canal with the microbiota in milk from the main udder compartment. Doyle et al. (2017) compared the microbiota in composite milk from individual cows, bulk tank milk, and the teat skin using $16 \mathrm{~S}$ rRNA amplicon sequencing. They found a large overlap between milk from individual cows, bulk tank, and teat skin microbiota when analyzed with multivariate methods, where teat skin was the most significant contributor of microbes in milk samples regardless of teat preparation and housing system. Derakhshani et al. (2018) compared the microbiota in the teat canal and mammary secretions before and after cows were subjected to a dry period. They found a higher bacterial diversity and a significant difference in composition of the microbiota in the teat canal compared with the microbiota in mammary secretions. Even though this topic has received attention, results and sampling techniques have not been conclusive.

This experiment was designed with the aim of assessing variation in the microbiota of milk samples taken using different sampling techniques before and after milking from healthy lactating dairy cows. We also aimed to compare the microbiota in milk with the microbiota on the teat end and in the teat canal. Our hypothesis was that milk collected directly from the teat cistern after milking would be the least diverse, contain the fewest numbers of taxa, be least affected by environmental bacteria, and be most representative of the microbiota in milk within the mammary gland. The milk sampling techniques used were chosen to collect milk that did or did not pass through the teat canal, as the teat canal may contain bacteria that can contaminate the milk sample. We hope that our results will be useful when selecting sampling methods in future milk microbiota studies.

\section{MATERIALS AND METHODS}

Five lactating dairy cows with no history of clinical mastitis in the ongoing lactation and a composite milk SCC below 100,000 cells/mL for 2 consecutive months were enrolled in the experiment. The cows were in lactation number 1 through 3 , on average had been milking for $187 \mathrm{~d}$ (range 145 to $283 \mathrm{~d}$ ), and were of either the Swedish Red $(\mathrm{n}=2)$ or the Swedish Holstein breed $(\mathrm{n}=3)$. Sampling was conducted at, and animals were provided by, the Swedish Livestock Research Center, Uppsala, Sweden. The sampling protocol was reviewed and approved by the Uppsala Animal Ethics Committee (protocol no: C99/13). On the day of sampling, cows were moved from their loose housing system to a smaller pen next to the sampling stall at least $1 \mathrm{~h}$ before the start of sampling, which occurred 6 to $9 \mathrm{~h}$ after the last milking. During sampling, the cows were restrained and offered feed and water, and the sampler wore nitrile gloves that were changed when dirty and between cows. Nine samples were taken from each udder quarter as follows, and as illustrated in Figure 1: the teat was wiped visibly clean with a moist paper towel and afterward dried with a paper towel before a teat end skin swab (E-Swab regular, Copan, Brescia, Italy) sample was taken. The swab was wiped against the skin in a $1-\mathrm{cm}$ radius from the teat canal several times before being placed in the provided transport medium (sample A). The teat end area surrounding the teat canal was then cleaned with 3 cotton pads moistened with $70 \%$ ethanol. A teat canal swab sample was taken by carefully inserting a thin urethra swab (E-Swab urethra, Copan) into the teat canal, using a twisting motion. After full insertion of the swab head $(20 \mathrm{~mm})$, the swab was twisted 180 degrees 3 times before being removed and placed in the provided transport medium (sample B). Thereafter, a hand-stripped milk sample was collected (sample C). All hand-stripped milk samples were collected in sterile $15-\mathrm{mL}$ tubes and had an approximate volume of 3 to $5 \mathrm{~mL}$ of milk. Next, 3 hand-stripped squirts of milk were discarded, and the teat end was cleaned with a cotton wad moistened with $70 \%$ ethanol before a conventional pre-milking handstripped milk sample was collected (sample D). Next, a teat canal cannula sample was taken by inserting a Tom Cat Catheter (3.5 Fr $1.16 \mathrm{~mm}$; Kendall, Tyco Healthcare, Mansfield, MA) through the teat canal into the teat cistern. The catheter was attached to a sterile syringe, and 3 to $5 \mathrm{~mL}$ of milk was collected by aspiration (sample E). The cow was then milked using a specially produced quarter-level milking machine provided by DeLaval (DeLaval AB, Tumba, Sweden). In the milking machine, milk from each quarter was collected in a separate vessel, and a sample was taken from each vessel after milking (sample K). The milking machine and vessels were thoroughly rinsed after milking each cow; $2.5 \mathrm{~L}$ of milk per udder quarter was the inclusion criterion for a complete milking. After milking, the cow was sedated by an intramuscular injection of xylazin $(0.05 \mathrm{mg} / \mathrm{kg}$ of BW, Rompun Vet, Bayer Animal Health, Monheim, Germany), the udder was manually massaged for $1 \mathrm{~min}$, and each teat end was cleaned with 3 cotton pads moistened with $70 \%$ ethanol. A post-milking hand-stripped milk sample (sample G) and a post-milking teat canal cannula sample (sample $\mathrm{H})$ were taken in the same manner as before milking. 
The sampling order of the hand-stripped milk samples and teat canal cannula samples before and after milking (samples D and $\mathrm{E}$, and $\mathrm{G}$ and $\mathrm{H}$ ) was alternated at cow level so that for 8 quarters the teat canal cannula samples were taken before the hand-stripped samples. Finally, a trans-teat wall needle aspirate milk sample was taken when the cow was fully sedated (sample I). The skin of the cranial side of the teat was cleaned with 3 cotton pads moistened with $70 \%$ ethanol, and the teat cistern was filled with milk before a $0.5 \times$ 16-mm needle attached to a sterile syringe was inserted through the teat wall and milk collected in the syringe. All samples were placed on ice directly after sampling, and within 45 min after sampling the milk samples were thoroughly mixed and divided into 3 aliquots. The milk aliquots and swab samples were kept cold on ice for 2 to $7 \mathrm{~h}$ before being stored at $-80^{\circ} \mathrm{C}$ until DNA extraction. One milk aliquot was kept cold overnight and used for aerobic bacterial culturing and SCC measurement.

Bacterial culturing was performed on milk samples $\mathrm{C}$ through I. Milk aliquots were processed and bacterial inoculation was performed on an ethanol-cleaned bench top, and only sterile equipment was used in contact with milk. For culturing, $10 \mu \mathrm{L}$ of milk was inoculated on agar plates with $5 \%$ bovine blood and $0.05 \%$ esculin (National Veterinary Institute, Uppsala, Sweden) and incubated aerobically at $37^{\circ} \mathrm{C}$. Growth on agar plates was evaluated after 24 and $48 \mathrm{~h}$ as no growth (0 to $2 \mathrm{cfu} / 10 \mu \mathrm{L})$ or growth $(>2 \mathrm{cfu} / 10 \mu \mathrm{L})$. Plates with growth were sent to the ISO 17025-accredited Mastitis Laboratory at the National Veterinary Institute, Uppsala, Sweden, for routine mastitis diagnostic evaluation. At the Mastitis Laboratory, quantity of cfu and number of phenotypically different cfu were evaluated and bacterial isolates identified to species level using MALDI-TOF, when appropriate. Milk SCC was measured using a DeLaval cell counter with a fluorescent microscopy-based method.

The DNA from swabs and milk samples was extracted using the Qiagen QIAamp DNA mini kit vacuum protocol (Qiagen, Valencia, CA). Milk aliquots $(1 \mathrm{~mL}$ each) were thawed on ice and centrifuged at $4^{\circ} \mathrm{C}$ and $13,000 \times g$ for $10 \mathrm{~min}$. The fat layer was carefully removed and the supernatant discarded. The remaining cell pellet was re-suspended in $500 \mu \mathrm{L}$ of TE50 buffer (10 m $M$ Tris-HCL, $50 \mathrm{~m} M$ EDTA, pH 8). Samples were subjected to enzymatic lysis by adding $100 \mu \mathrm{L}$ of a mixture consisting of $50 \mu \mathrm{L}$ of lysozyme (Sigma-Aldrich, St. Louis, MO; $10 \mathrm{mg} / \mathrm{mL}$ in nuclease-free water), $6 \mu \mathrm{L}$ of mutanolysin (Sigma-Aldrich; $25 \mathrm{kU} / \mathrm{mL}$ in nucleasefree water), $3 \mu \mathrm{L}$ of lysostaphin $(4,000 \mathrm{U} / \mathrm{mL}$ in 20 $\mathrm{m} M$ sodium acetate; Sigma-Aldrich), and $41 \mu \mathrm{L}$ TE50
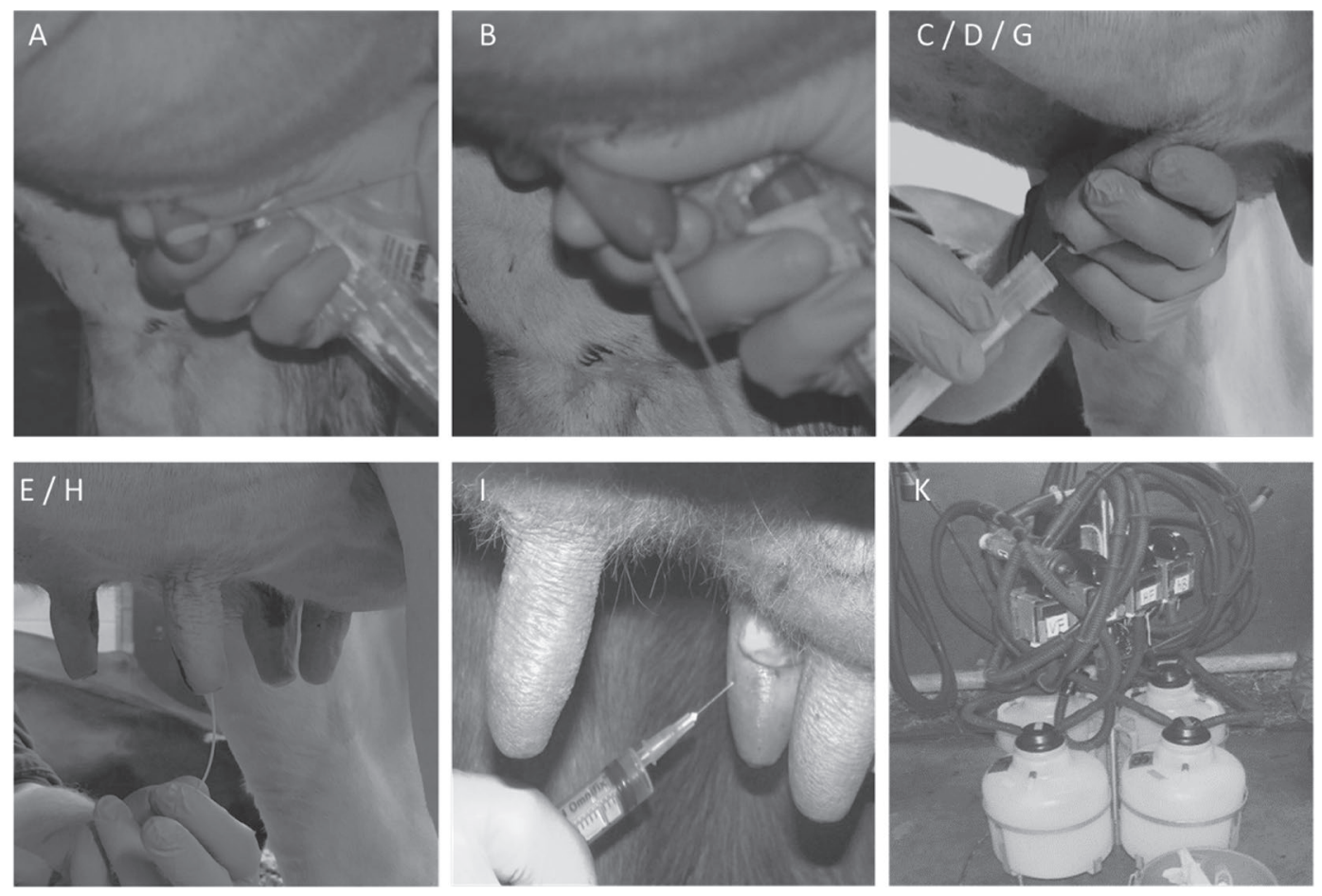

Figure 1. Illustration of samples taken during the experiment; letters correspond to sample description in text. Teat end swab (A), teat canal swab (B), hand-stripped milk samples (C, D, G), teat canal cannula samples (E, H), trans-teat wall needle aspirate (I), quarter milk machine sample (K). Samples A-E were taken directly before machine milking; samples G-I were taken directly after machine milking; sample K is a composite milk sample from individual quarters. Sample I was collected from 18 quarters, and all other samples were collected from 20 quarters. 
for $1 \mathrm{~h}$ at $37^{\circ} \mathrm{C}$ on a dry heat block, before physical disruption by bead-beating with $0.1-\mathrm{mm}$ zirconia/ silica beads (BioSpec Products, Bartlesville, OK) for 1 min on setting 5 using a FastPrep FP120 (Qbiogene, Carlsbad, CA). The DNA was subsequently extracted using a modified protocol of the QIAamp DNA Mini Kit (Qiagen), whereby $100 \mu \mathrm{L}$ of $3 M$ sodium acetate, $\mathrm{pH} 5.5$, was added to the lysate before the addition to the spin column. The TE50 $(0.5 \mathrm{~mL})$ was used as a negative control. Extracted DNA was eluted in $50 \mu \mathrm{L}$ of nuclease-free water and stored at $-80^{\circ} \mathrm{C}$ until further analysis. For DNA extraction from the swabs, the ends of swabs were cut into sterile $1.5-\mathrm{mL}$ tubes containing $500 \mu \mathrm{L}$ of TE50 buffer and vortexed, and then the fluid was transferred to a new microcentrifuge tube. Fluid samples were then processed as described above.

Bacterial DNA was amplified in a 2-step PCR. In the first step, the V1-V3 hypervariable region of the 16S rRNA gene was amplified using 7-fold degenerate forward and reverse primers, previously described by Lackey et al. (2017). The first PCR mixture contained $12.5 \mu \mathrm{L}$ of Q5 Hot Start High-Fidelity $2 \times$ Master Mix (New England Biolabs Inc., Ipswich, MA), $0.25 \mu \mathrm{L}$ each of $10 \mu M$ forward and reverse primers (Integrated DNA Technologies, Coralville, IA), $2 \mu \mathrm{L}$ of DNA extract, and $8 \mu \mathrm{L}$ of nuclease-free water. We ran PCR in a thermocycler under the following conditions: initial denaturation at $98^{\circ} \mathrm{C}$ for $30 \mathrm{~s}$, then 15 cycles of $98^{\circ} \mathrm{C}$ for $10 \mathrm{~s}, 51^{\circ} \mathrm{C}$ for $20 \mathrm{~s}$, and $72^{\circ} \mathrm{C}$ for $20 \mathrm{~s}$. After the 15 cycles were completed, the thermocycler was paused, and 2 $\mu \mathrm{L}$ of the second PCR primers $(2 \mu M)$ with dual-index barcodes and Illumina sequencing adapters (University of Idaho Institute for Bioinformatics and Evolutionary Studies Genomics Resources Core Facility, Moscow, ID) were added. The thermocycler program was then resumed with an initial denaturation at $98^{\circ} \mathrm{C}$ for $30 \mathrm{~s}$, and an additional 15 cycles of $98^{\circ} \mathrm{C}$ for $10 \mathrm{~s}, 60^{\circ} \mathrm{C}$ for 20 $\mathrm{s}$, and $72^{\circ} \mathrm{C}$ for $20 \mathrm{~s}$ were performed, followed by a final extension at $72^{\circ} \mathrm{C}$ for $2 \mathrm{~min}$. The reaction was then held at $4^{\circ} \mathrm{C}$ until storage at $-20^{\circ} \mathrm{C}$. The quality of the PCR amplicons was evaluated via agarose gel electrophoresis or on a QIAxcel DNA screening cartridge (Qiagen), or both in combination. Samples were deemed acceptable if they had a band of appropriate size, low abundance of primer-dimer bands, and absence of unwanted bands. If samples amplified poorly, re-amplification was attempted. Overall, 6 samples had to be re-amplified to obtain enough DNA for equimolar pooling. DNA was quantified using the Qubit 2.0 Fluorometer and the Qubit dsDNA High-Sensitivity Assay (Thermo Fisher Scientific, Waltham, MA). Samples were pooled to contain $50 \mathrm{ng}$ of DNA from each sample and submitted to the University of Idaho Genomics Resources Core for sequencing. At the core, the amplicon pools were size-selected using AMPure beads (Beckman Coulter, Brea, CA) and then quantified using a KAPA Illumina library quantification kit (KAPA Biosystems, Wilmington, MA) and the Applied Biosystems StepOne Plus real-time PCR system. Sequences were then obtained using an Illumina MiSeq v3 paired-end 300 bp protocol for 600 cycles.

Raw DNA sequence reads were demultiplexed, joined, and classified using the custom Python application dbcAmplicons (https://github.com/msettles/ dbcAmplicons) as previously described (Carrothers et al., 2015). Two data sets were used for data analysis. The first included all identified taxa and absolute number of reads per sample, and the second included relative abundance, and taxa identified to a higher taxonomical level than genus were aggregated into "other." Descriptive analysis on sequencing results, statistical calculations, and multivariate analyses were performed using Microsoft Excel 2016 (Microsoft Corp., Redmond, WA), R (R Core Team 2019), and PAST (Hammer et al., 2001). Differences between samples were explored via principal coordinates analysis (PCoA) using Bray Curtis similarity as a distance measure and statistically tested with analysis of similarity (ANOSIM). An ANOSIM is a nonparametric test based on ranked dissimilarity; the R-value given is a comparative measure of the degree of separation between sites or samples, where an R-value close to 0 indicates no separation between sites or samples, and an R-value of 1 indicates complete separation between sites or samples (Clarke, 1993). The ANOSIM allows statistical testing for a significant difference between 2 or more groups. For all analyses, significance level was set at $P<0.05$.

\section{RESULTS}

Samples A through $\mathrm{H}$ and $\mathrm{K}$ were collected from 20 quarters, and the needle aspirate (sample I) was collected from 18 quarters, giving a total of 178 collected samples. Bacterial culturing was performed on 118 milk samples (samples C through I). Ten (8\%) of the milk samples had growth of more than $2 \mathrm{cfu} / 10 \mu \mathrm{L}$ of milk, of which 6 samples (from the same quarter) had pure growth of Staphylococcus epidermidis and were judged as subclinically infected. Four milk samples had sparse growth of a mixed bacterial flora (defined as growth of 3 or more phenotypically different cfu); 3 of these samples were collected as hand-stripped milk samples after milking (sample $\mathrm{G}$ ), and 3 of the samples were collected from the same cow (Table 1). Overall, the SCC ranged from 0 to 385,000 cells $/ \mathrm{mL}$ (Table 1 ), with an average of 60,000 cells $/ \mathrm{mL}$ (CV 23.6\%). Three milk samples collected via needle aspirate were contaminated with blood, affecting the SCC (leukocyte) 
Table 1. Milk somatic cell count $(\mathrm{SCC} \times 1,000 / \mathrm{mL})$ and bacterial findings by culture per cow, udder quarter (Q1-Q4), and sample type ${ }^{1}$

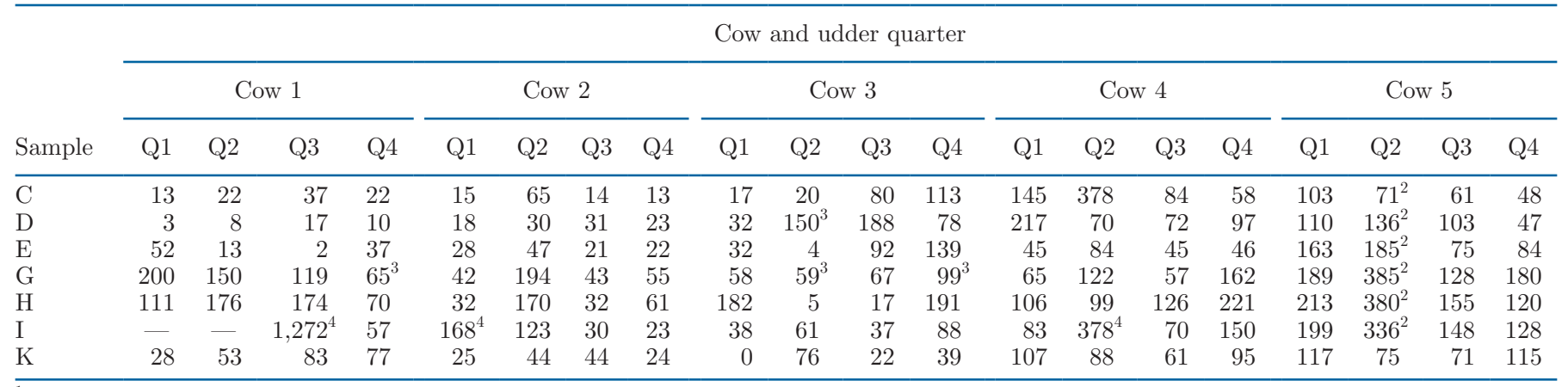

${ }^{1}$ Hand-stripped milk samples $(\mathrm{C}, \mathrm{D}, \mathrm{G})$; teat canal cannula samples (E, H); trans-teat wall needle aspirate (I); quarter milk machine sample (K). Samples C-E were taken directly before machine milking; samples G-I were taken directly after machine milking. Bacterial culturing was performed on samples C-I.

${ }^{2}$ Growth of Staphylococcus epidermidis.

${ }^{3}$ Growth of mixed bacterial flora.

${ }^{4}$ Blood-contaminated milk samples.

values, and were consequently excluded from the SCC analysis. The SCC varied between consecutively taken samples using different techniques within the same udder quarter. The largest difference in SCC between 2 samples taken directly after each other, either as a hand-stripped sample or with a teat canal cannula, within the same milk fraction (D vs. $E$ or $G$ vs. H), was 172,000 cells $/ \mathrm{mL}$, with an average difference of \pm 28,000 cells/mL (CV 32.4\%), and with higher values for hand-stripped samples in $45 \%$ (18 out of 40 ) of the comparisons (Table 1).

Sequencing produced a total of 2,689,894 reads from 177 samples, with an average of 15,197 $\pm 13,889$ (mean $\pm \mathrm{SD}$ ) reads per sample. In total 1,044 taxa were identified, of which 851 taxa were assigned to a genus and 193 taxa were classified to a higher taxonomical level. Analyses of Chao1 richness revealed that the mean genus richness was 90 taxa for all samples. Mean genus richness was significantly higher in sample A (138 genera) than in samples B through I (mean 78 genera), and in K (124 genera) compared with samples E through I (mean 70 genera; Bonferroni-corrected Mann-Whitney pairwise). Genera richness was numerically lower in samples H (57 genera) and I (64 genera), although not significantly (Figure 2). Shannon and Simpson diversity did not differ between the different sample types. For Shannon diversity the range was 2.4 to 2.83 (samples $\mathrm{H}$ and A, respectively) with a mean of 2.66 , and for Simpson diversity the range was 0.78 to 0.86 (samples $\mathrm{H}$ and A, respectively) with a mean of 0.83 . Data analysis with PCoA based on Bray Curtis similarity index revealed a mixed appearance: in individual cows, samples A, B, and K tended to cluster separately, whereas a large overlap occurred for samples $\mathrm{C}$ through I (Supplemental Figure S1; https://doi.org/10.3168/jds .2019-17783). A PCoA of the whole data set revealed a large overlap among all samples, an effect largely attributed to the udder quarter suffering from subclinical mastitis and with bacterial growth of $S$. epidermidis in all milk samples (Supplemental Figure S2A; https:// doi.org/10.3168/jds.2019-17783). Because the aim was to study healthy udder quarters, data from this udder quarter was omitted from further analyses (Supplemental Figure S2C; https://doi.org/10.3168/jds.2019 -17783). A PCoA of the curated data set revealed a similar mixed appearance as analyses for individual cows, with separate clusters for samples A, B, and K, and a large overlap for samples $\mathrm{C}$ through I (Figure 3). An ANOSIM revealed that the swab samples and milk sample taken from the milking machine (samples A, B, and K, respectively) differed significantly in their bacterial composition from milk samples taken directly from the teat (samples C through I), and detected no significant differences in the bacterial composition for samples C through I (Figure 3).

The relative abundance of the 10 most abundant genera were further analyzed in the 4 groups of samples identified as significantly different (group of samples A, $\mathrm{B}, \mathrm{C}$ through I, and K) by PCoA and ANOSIM (Figure 4). All the 10 genera were present in all groups but not in all samples. The distribution of each genera within the different groups and statistical difference between groups of milk samples are shown in Figure 4.

\section{DISCUSSION}

Assessing milk microbiota by $16 \mathrm{~S}$ rRNA gene sequencing is complex (Metzger et al., 2018b) and prone to introduction of biases and contamination (Salter et al., 2014; Pollock et al., 2018). Although several studies have described a microbiota in bovine milk (see Metzger et al., 2018b, for review) doubt about the concept of a 
microbiota in healthy animals has also been expressed (Rainard, 2017). This study was designed to assess effects of sampling technique and variation between milk fractions, rather than to describe the milk microbiota in detail.

The PCoA revealed that some samples clustered separately, whereas a prominent overlap and large variation occurred in other samples, differences that were further evaluated using ANOSIM. From the ANOSIM we concluded that swab samples (A, B) and quarter composite milk samples $(\mathrm{K})$ differed significantly from each other and all other samples, whereas no significant difference in bacterial community composition was found for samples taken directly from the udder quarter (samples C through I). Univariate tests were used to identify

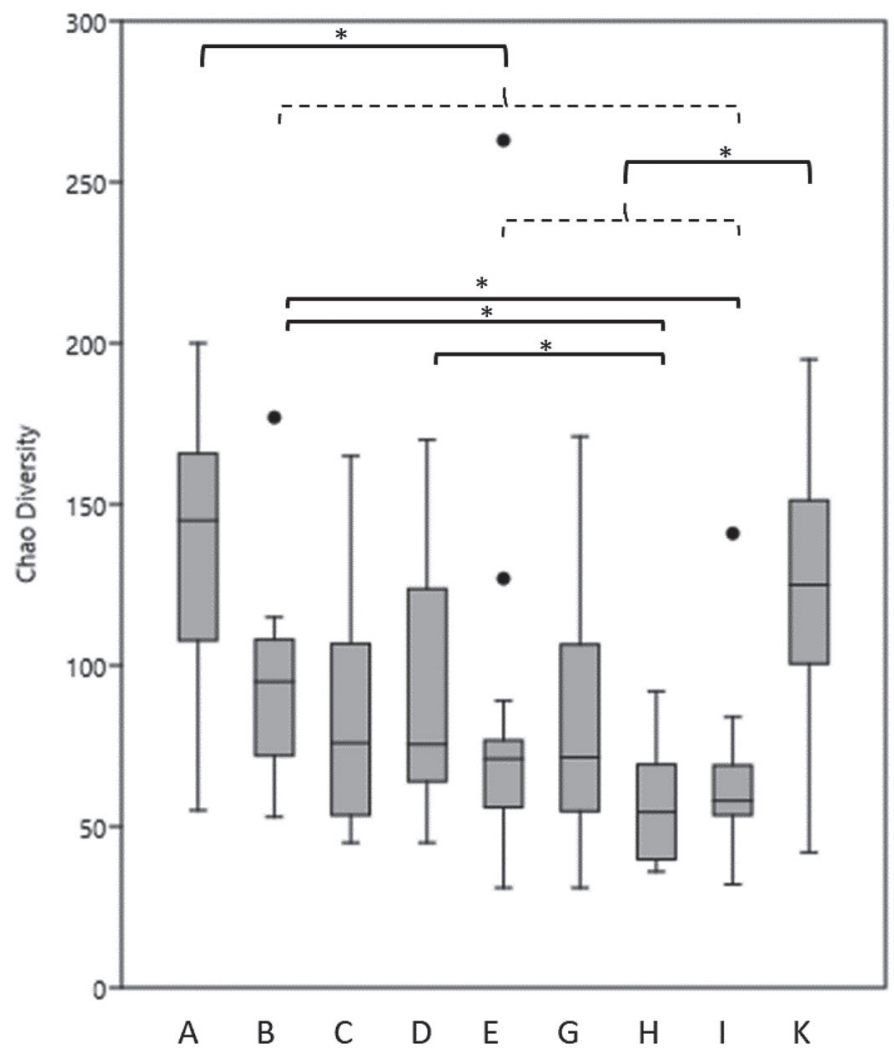

Figure 2. Chao1 richness in samples taken with different techniques before and after milking. Teat end swab (A), teat canal swab (B), hand-stripped milk samples (C, D, G), teat canal cannula samples $(\mathrm{E}, \mathrm{H})$, trans-teat wall needle aspirate $(\mathrm{I})$, quarter milk machine sample $(\mathrm{K})$. Samples A-E were taken directly before machine milking; samples G-I were taken directly after machine milking; sample $\mathrm{K}$ is a composite milk sample from individual quarters. Sample I was collected from 18 quarters, and all other samples were collected from 20 quarters. For boxes, the $25-75 \%$ quartiles are in the box, and the median is shown as a horizontal line; the highest values less than 1.5 box height are shown as whiskers, and outliers more than 1.5 box heights are shown as dots. Brackets with stars indicate that boxes are significantly different $(P<0.05$ in Bonferroni-corrected Mann-Whitney pairwise). Samples under dotted brackets are all significantly different from samples A and K, respectively. which taxa contributed to the separation of groups in the PCoA and ANOSIM. The univariate tests revealed several significant differences. Bacteria belonging to the genera Staphylococcus and Corynebacterium are commonly isolated in bovine milk (Pitkälä et al., 2004) and are classified as contagious mastitis pathogens that have the ability to colonize the mammary gland and teat canal (Fox and Gay, 1993). In the present study Staphylococcus and Corynebacterium were found in higher abundance in swab samples from the teat skin and teat canal compared with the milk samples. The genera Stenotrophomonas and Pseudomonas were significantly more abundant in the udder composite milk samples (sample K) than in any other sample. Species from both genera have previously been reported from animals (Conly and Shafran, 1996; Peix et al., 2009) but are more commonly found in water and soil. An unexpected finding in this study was the presence of the genus Dyella in the top 10 most abundant bacteria. Findings of Dyella have, to the best of our knowledge, never been reported in milk from lactating bovines, and its presence needs to be confirmed with other methods. The genera Delftia, Aerococcus, Acinetobacter, and Janthinobacterium all appeared in low abundance and have previously been described in milk. Delftia has been reported as a member of the bovine milk microbiota (Oikonomou et al., 2014) using culture-independent techniques and in goat milk using culture-dependent techniques (Callon et al., 2007). Acinetobacter has been found in bulk tank milk (Hahne et al., 2019), and species belonging to the genus Aerococcus have been described as causative agents for subclinical mastitis (Sun et al., 2017). Janthinobacterium are known to cause spoilage of milk and may recontaminate milk after pasteurization in dairy plants (Eneroth et al., 2000).

Contamination can be a problem in microbiota studies and may be introduced during all phases of sample handling as well as in the laboratory (Salter et al., 2014; Dahlberg et al., 2019). In this study, negative controls from the barn environment and milking machine were not collected, and negative controls from DNA extraction and PCR reaction did not contain any PCR products and were not included in the sequencing, as this was the standard procedure in our laboratory at the time of sequencing. Our ability to detect contaminants in this data set is therefore limited. It is likely that environmental contamination explains some of the differences in the found microbiota, because teat end swab and teat canal swab samples (samples A and B) were more exposed to the barn environment than other samples. Also, the composite milk sample (sample K) was exposed to the environment in the milking machine, where water residues from washing could have contributed to differences in the microbiota. Further 
we cannot exclude Dyella as an introduced contamination, because this genus has never been isolated in milk before, and the high number of identified bacterial taxa can also be the result of contamination of samples. Another limitation in this study is the number of animals that were sampled. However, even with the low numbers and high variation seen in the microbial composition of the samples, we were able to detect differences in overall bacterial composition obtained with different sampling techniques.

The higher genera richness on the teat end and in machine milk is in line with Metzger et al. (2018a), who found greater Chao richness in composite samples than in hand-stripped and needle aspirate milk samples but no difference between hand-stripped and needle aspi- rate milk samples. Previous studies (Bexiga et al., 2011; Hiitiö et al., 2016; Friman et al., 2017) found reduced numbers of species in samples taken when bypassing the teat canal. In this study, similar tendencies were observed but were not found to be statistically significant. As such, our hypothesis could not be confirmed.

In this study 10 milk samples had growth of more than $2 \mathrm{cfu}$ on $10 \mu \mathrm{L}$ of cultured milk. In mastitis diagnostics, growth of colonies of the same organism is indicative of an intramammary infection, but if the colonies are few or phenotypically different, they may be the result of contamination of the sample (Oliver et al., 2004). In this study, 6 milk samples from the same quarter had growth of $S$. epidermidis and were diagnosed as intramammary infection; 4 samples had

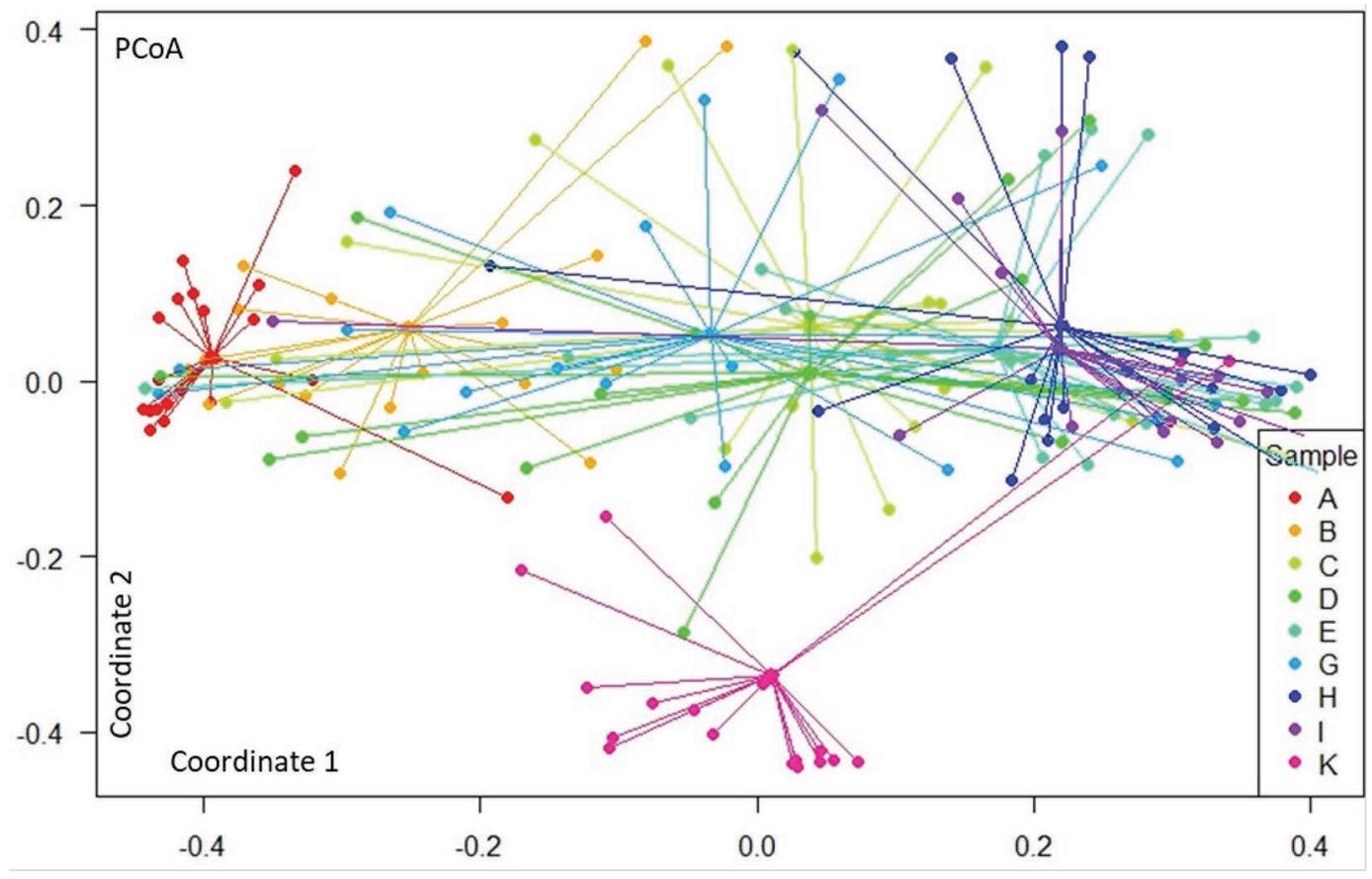

\begin{tabular}{|c|c|c|c|c|c|c|c|c|c|}
\hline ANOSIM & A & B & C & D & $E$ & G & $\mathrm{H}$ & I & K \\
\hline A & & 0.029 & 0.004 & 0.004 & 0.004 & 0.004 & 0.004 & 0.004 & 0.004 \\
\hline $\mathrm{B}$ & 0.134 & 7 & 0.007 & 0.011 & 0.004 & 0.043 & 0.004 & 0.004 & 0.004 \\
\hline C & 0.435 & 0.203 & 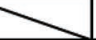 & 1.0 & 1.0 & 1.0 & 1.0 & 1.0 & 0.004 \\
\hline D & 0.417 & 0.228 & -0.037 & 7 & 1.0 & 1.0 & 1.0 & 1.0 & 0.004 \\
\hline$E$ & 0.699 & 0.516 & 0.008 & 0.013 & 7 & 1.0 & 1.0 & 1.0 & 0.004 \\
\hline G & 0.357 & 0.183 & -0.013 & -0.009 & 0.086 & 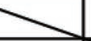 & 0.086 & 0.140 & 0.004 \\
\hline $\mathrm{H}$ & 0.829 & 0.610 & 0.060 & 0.070 & -0.033 & 0.176 & 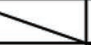 & 1.0 & 0.004 \\
\hline 1 & 0.860 & 0.639 & 0.034 & 0.057 & -0.069 & 0.204 & -0.041 & & 0.004 \\
\hline K & 0.837 & 0.679 & 0.502 & 0.493 & 0.634 & 0.606 & 0.643 & 0.663 & \\
\hline
\end{tabular}

Figure 3. Principal coordinates analysis (PCoA) and analysis of similarity (ANOSIM) for bacterial community composition. Bray Curtis similarity index used for both analyses; udder quarter with subclinical mastitis omitted. Teat end swab (A), teat canal swab (B), hand-stripped milk samples (C, D, G), teat canal cannula samples (E, H), trans-teat wall needle aspirate (I), quarter milk machine sample (K). Samples A-E were taken directly before machine milking; samples G-I were taken directly after machine milking; sample $\mathrm{K}$ is a composite milk sample from individual quarters. Sample I was collected from 18 quarters, and all other samples were collected from 20 quarters. ANOSIM with 9,999 permutations, Bonferroni-corrected $P$-values above diagonal and ANOSIM R-values below the diagonal. Significant $P$-values marked in italic. 

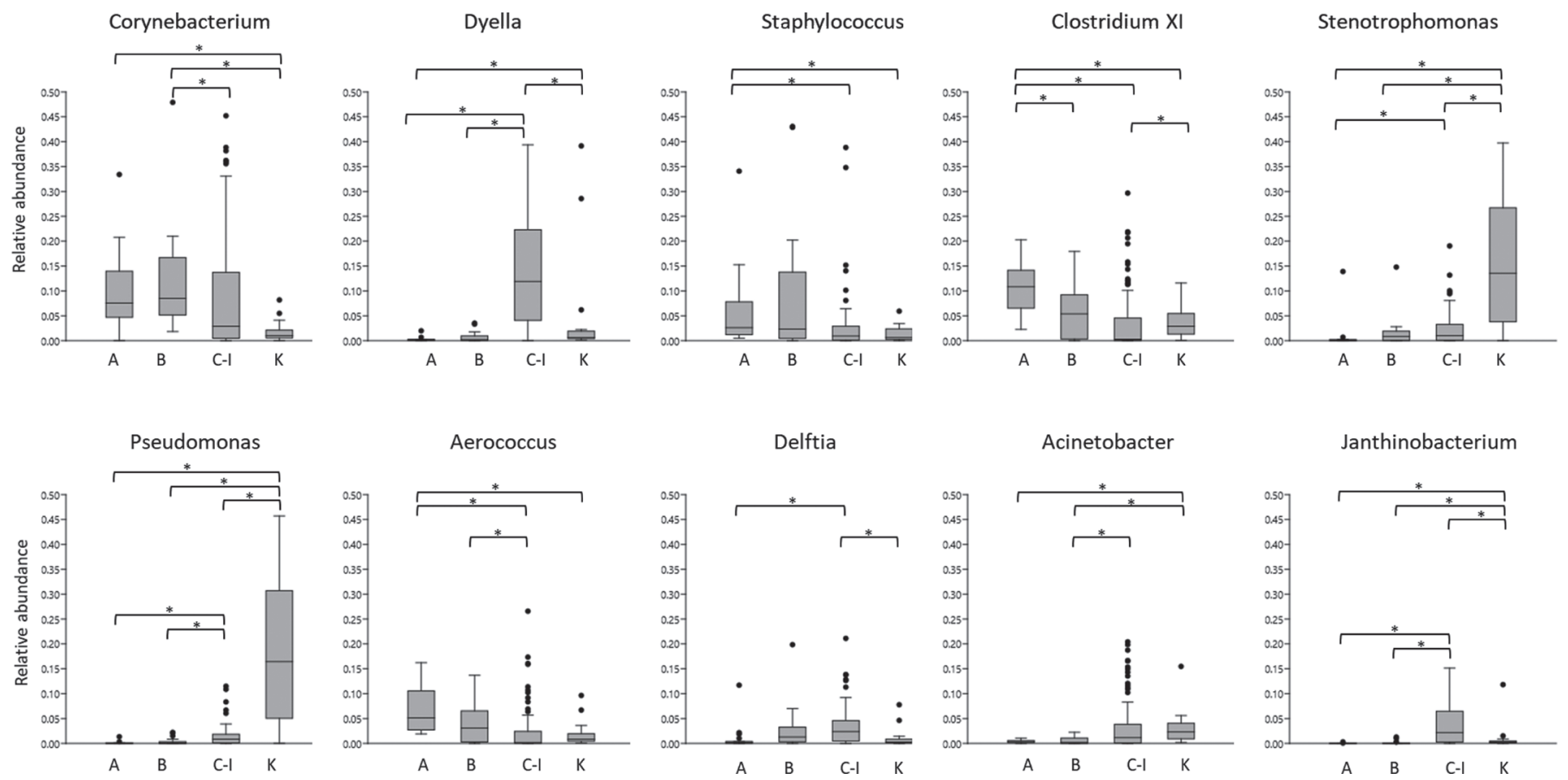

Figure 4. Box plots of the 10 most abundant genera and their relative abundance in 4 groups of milk samples. Groups of milk samples [sample A $(\mathrm{n}=20), \mathrm{B}(\mathrm{n}=20), \mathrm{C}-\mathrm{I}(\mathrm{n}=117)$, and $\mathrm{K}(\mathrm{n}=20)]$ were identified by principal coordinates analysis and analysis of similarity as having different bacterial compositions. Brackets with asterisks indicate that boxes are significantly different $(P<0.05$ in Bonferroni-corrected MannWhitney pairwise). For boxes, the 25-75\% quartiles are in the box, and the median is shown as a horizontal line; the highest values less than 1.5 box height are shown as whiskers, and outliers more than 1.5 box heights are shown as dots. Relative abundance on y-axis is truncated at 0.5 .

growth of phenotypically different cfu and would thus, according to National Mastitis Council guidelines (Oliver et al., 2004), likely be the result of contamination. Omitting the samples with growth of S. epidermidis did, but omitting the samples with mixed bacterial growth did not, affect the overall appearance in the PCoA (Supplemental Figure S2; https://doi.org/10 .3168/jds.2019-17783). An unexpected finding in this study was the large difference in SCC in consecutivelytaken samples using different techniques. According to the manufacturer, the repeatability in SCC measurements of the cell counter is 7 to $12 \%$, depending on the SCC range of the sample. One could hypothesize that hand-stripped samples would have a higher SCC due to scaling of epithelial cells from the teat cistern and teat canal, but such argumentation is unlikely due to the fact that higher SCC was found as often in milk samples taken with a cannula (Table 1). Consequently, the observed phenomenon requires further investigation.

\section{CONCLUSIONS}

The results of this study show that for aseptic milk samples taken directly from the teat as hand-stripped milk samples, protected teat canal cannula milk sam- ples, or trans-teat wall needle aspirate milk samples, before or after milking, microbiota analysis displays similar results. The stated techniques will, as such, according to our results, all give a representative sample for analysis of the microbiota in milk. Swab samples collected from either the teat end or the teat canal and composite milk samples had different bacterial community compositions compared with milk samples and, as such, are not representative for the microbiota in milk.

\section{ACKNOWLEDGMENTS}

The Swedish Research Council Formas (Stockholm, Sweden) is gratefully acknowledged for financial support (2012-1365-22729-42). The Fulbright Program and Erasmus Mundus Food of Life supported M. A. McGuire's sabbatical to the Swedish University of Agricultural Sciences, Uppsala, Sweden. Research reported in this publication was also supported by an Institutional Development Award (IDeA) from the National Institute of General Medical Sciences (Bethseda, MD) of the National Institutes of Health (Bethseda, MD) under grant number P30 GM103324. Additionally, the authors thank Jessica Zachek and Kimberly Lackey, both at the Department of Animal and Veterinary Science, University of Idaho (Moscow, ID), for their assistance 
with sample processing. The authors have not stated any conflicts of interest.

\section{REFERENCES}

Bexiga, R., H. Pereira, O. Pereira, A. Leitao, C. Carneiro, K. A. Ellis, and C. L. Vilela. 2011. Observed reduction in recovery of Corynebacterium spp. from bovine milk samples by use of a teat cannula. J. Dairy Res. 78:9-14. https://doi.org/10.1017/S0022029910000609.

Braem, G., S. De Vliegher, B. Verbist, M. Heyndrickx, F. Leroy, and L. De Vuyst. 2012. Culture-independent exploration of the teat apex microbiota of dairy cows reveals a wide bacterial species diversity. Vet. Microbiol. 157:383-390. https://doi.org/10.1016/j vetmic.2011.12.031.

Callon, C., F. Duthoit, C. Delbes, M. Ferrand, Y. Le Frileux, R. De Cremoux, and M. C. Montel. 2007. Stability of microbial communities in goat milk during a lactation year: Molecular approaches. Syst. Appl. Microbiol. 30:547-560. https://doi.org/10.1016/j .syapm.2007.05.004.

Carrothers, J. M., M. A. York, S. L. Brooker, K. A. Lackey, J. E. Williams, B. Shafii, W. J. Price, M. L. Settles, M. A. McGuire, and M. K. McGuire. 2015. Fecal microbial community structure is stable over time and related to variation in macronutrient and micronutrient intakes in lactating women. J. Nutr. 145:2379-2388. https:/ /doi.org/10.3945/jn.115.211110.

Clarke, K. R. 1993. Non-parametric multivariate analyses of changes in community structure. Austral Ecol. 18:117-143. https://doi .org/10.1111/j.1442-9993.1993.tb00438.x.

Conly, J., and S. Shafran. 1996. Pseudo-, Xantho-, and now Stenotrophomonas maltophilia: New kid on the block. Can. J. Infect. Dis. 7:99-100. https://doi.org/10.1155/1996/585141.

Dahlberg, J., L. Sun, K. Persson Waller, K. Östensson, M. McGuire, S. Agenäs, and J. Dicksved. 2019. Microbiota data from low biomass milk samples is markedly affected by laboratory and reagent contamination. PLoS One 14:e0218257. https://doi.org/10.1371/ journal.pone.0218257.

Derakhshani, H., J. C. Plaizier, J. De Buck, H. W. Barkema, and E. Khafipour. 2018. Composition of the teat canal and intramammary microbiota of dairy cows subjected to antimicrobial dry cow therapy and internal teat sealant. J. Dairy Sci. 101:10191-10205. https://doi.org/10.3168/jds.2018-14858.

Doyle, C. J., D. Gleeson, P. W. O'Toole, and P. D. Cotter. 2017. Impacts of seasonal housing and teat preparation on raw milk microbiota: A high-throughput sequencing study. Appl. Environ. Microbiol. 83:e02694-16. https://doi.org/10.1128/AEM.02694-16.

Eneroth, Å., S. Ahrné, and G. Molin. 2000. Contamination routes of gram-negative spoilage bacteria in the production of pasteurised milk, evaluated by randomly amplified polymorphic DNA (RAPD). Int. Dairy J. 10:325-331. https://doi.org/10.1016/S0958 $-6946(00) 00055-8$.

Falentin, H., L. Rault, A. Nicolas, D. S. Bouchard, J. Lassalas, P. Lamberton, J. M. Aubry, P. G. Marnet, Y. Le Loir, and S. Even. 2016. Bovine teat microbiome analysis revealed reduced alpha diversity and significant changes in taxonomic profiles in quarters with a history of mastitis. Front. Microbiol. 7:480. https://doi.org/ 10.3389/fmicb.2016.00480.

Fox, L. K., and J. M. Gay. 1993. Contagious mastitis. Vet. Clin. North Am. Food Anim. Pract. 9:475-487. https://doi.org/10.1016/S0749 -0720(15)30615-0.

Friman, M., H. Hiitiö, M. Niemi, J. Holopainen, S. Pyörälä, and H. Simojoki. 2017. The effect of a cannula milk sampling technique on the microbiological diagnosis of bovine mastitis. Vet. J. 226:57-61. https://doi.org/10.1016/j.tvjl.2017.07.003.

Gill, J. J., P. M. Sabour, J. Gong, H. Yu, K. E. Leslie, and M. W. Griffiths. 2006. Characterization of bacterial populations recovered from the teat canals of lactating dairy and beef cattle by $16 \mathrm{~S}$ rRNA gene sequence analysis. FEMS Microbiol. Ecol. 56:471-481. https://doi.org/10.1111/j.1574-6941.2006.00091.x.
Hahne, J., D. Isele, J. Berning, and A. Lipski. 2019. The contribution of fast growing, psychrotrophic microorganisms on biodiversity of refrigerated raw cow's milk with high bacterial counts and their food spoilage potential. Food Microbiol. 79:11-19. https://doi.org/ 10.1016/j.fm.2018.10.019.

Hammer, O., D. Harper, and P. Ryan. 2001. PAST: Paleontological statistics software package for education and data analysis. Palaeontol. Electronica 4:9. http://palaeo-electronica.org/2001_1/past/ issue1_01.htm.

Hiitiö, H., H. Simojoki, P. Kalmus, J. Holopainen, S. Pyörälä, and S. Taponen. 2016. The effect of sampling technique on PCRbased bacteriological results of bovine milk samples. J. Dairy Sci. 99:6532-6541. https://doi.org/10.3168/jds.2015-10811.

Lackey, K. A., J. E. Williams, W. J. Price, J. M. Carrothers, S. L. Brooker, B. Shafii, M. A. McGuire, and M. K. McGuire. 2017. Comparison of commercially-available preservatives for maintaining the integrity of bacterial DNA in human milk. J. Microbiol. Methods 141:73-81. https://doi.org/10.1016/j.mimet.2017.08.002.

Metzger, S. A., L. L. Hernandez, J. H. Skarlupka, G. Suen, T. M. Walker, and P. L. Ruegg. 2018a. Influence of sampling technique and bedding type on the milk microbiota: Results of a pilot study. J. Dairy Sci. 101:6346-6356. https://doi.org/10.3168/jds.2017 $-14212$.

Metzger, S. A., L. L. Hernandez, G. Suen, and P. L. Ruegg. 2018b. Understanding the milk microbiota. Vet. Clin. North Am. Food Anim. Pract. 34:427-438. https://doi.org/10.1016/j.cvfa.2018.06 .003 .

Oikonomou, G., M. L. Bicalho, E. Meira, R. E. Rossi, C. Foditsch, V. S. Machado, A. G. Teixeira, C. Santisteban, Y. H. Schukken, and R. C. Bicalho. 2014. Microbiota of cow's milk; Distinguishing healthy, sub-clinically and clinically diseased quarters. PLoS One 9:e85904. https://doi.org/10.1371/journal.pone.0085904.

Oliver, S. P., R. N. Gonzalez, J. S. Hogan, B. M. Jayarao, and W. E. Owens. 2004. Microbiological Procedures for the Diagnosis of Bovine Udder Infection and Determination of Milk Quality. 4th ed. National Mastitis Council (NMC) Inc, Verona, WI.

Peix, A., M. H. Ramirez-Bahena, and E. Velazquez. 2009. Historical evolution and current status of the taxonomy of genus Pseudomonas. Infect. Genet. Evol. 9:1132-1147. https://doi.org/10.1016/j .meegid.2009.08.001.

Pitkälä, A., M. Haveri, S. Pyörälä, V. Myllys, and T. Honkanen-Buzalski. 2004. Bovine mastitis in Finland 2001-Prevalence, distribution of bacteria, and antimicrobial resistance. J. Dairy Sci. 87:2433-2441. https://doi.org/10.3168/jds.S0022-0302(04)73366 -4 .

Pollock, J., L. Glendinning, T. Wisedchanwet, and M. Watson. 2018. The madness of microbiome: Attempting to find consensus "best practice" for $16 \mathrm{~S}$ microbiome studies. Appl. Environ. Microbiol. 84:e2627-17. https://doi.org/10.1128/AEM.02627-17.

R Core Team. 2019. R: A language and environment for statistical computing. R Foundation for Statistical Computing, Vienna, Austria.

Rainard, P. 2017. Mammary microbiota of dairy ruminants: Fact or fiction? Vet. Res. 48:25. https://doi.org/10.1186/s13567-017-0429 -2 .

Salter, S. J., M. J. Cox, E. M. Turek, S. T. Calus, W. O. Cookson, M. F. Moffatt, P. Turner, J. Parkhill, N. J. Loman, and A. W. Walker. 2014. Reagent and laboratory contamination can critically impact sequence-based microbiome analyses. BMC Biol. 12:87. https:// doi.org/10.1186/s12915-014-0087-z.

Sun, M., J. Gao, T. Ali, D. Yu, S. Zhang, S. U. Khan, S. Fanning, and B. Han. 2017. Characteristics of Aerococcus viridans isolated from bovine subclinical mastitis and its effect on milk SCC, yield, and composition. Trop. Anim. Health Prod. 49:843-849. https://doi .org/10.1007/s11250-017-1271-2.

Verdier-Metz, I., G. Gagne, S. Bornes, F. Monsallier, P. Veisseire, C. Delbes-Paus, and M. C. Montel. 2012. Cow teat skin, a potential source of diverse microbial populations for cheese production. Appl. Environ. Microbiol. 78:326-333. https://doi.org/10.1128/ AEM.06229-11. 